\section{ÜBER DIE KLINISCHE VERWERTBARKEIT DER SERUMHITZEKOAGULATION.}

\author{
Von \\ Prof. Dr. Georg Rosenow. \\ Aus der Medizinischen Universitätsklinik Königsberg i. Pr. (Dir. Geh.-Rat \\ Prof. Dr. Matthes.)
}

Mittels der von Herrn DR. R. L. MAYER ausgearbeiteten und durch ihn näher begründeten Methodik (s, die vorstehende Mitteilung) der Serumhitzekoagulation, habe ich gemeinschaftlich mit ihm bei einer Anzahl Normaler und Serumkranker den Koagulationspunkt (Ko. P.) und im gleichen Serum, das durch Venenpunktion gewonnen wurde, refraktometrisch den Eiweißgehalt bestimmt. (Bei der Refraktometrie haben mich Fräulein Dr. LANGANkE, Med. Prakt. an unserer Klinik und Herr Dr. JAGuTtis freundlichst unterstützt). Es sind auf diese Weise bisher etwa $5^{\circ}$ Sera untersucht worden. Aus dieser kleinen Zahl lassen sich bindende Schlüsse nicht ziehen. Einige auffallende Ergebnisse möchte ich aber schon jetzt kurz mitteilen. Bei der Mehrzahl der untersuchten Personen lagen die Ko. P. ebenso die Refraktometerwerte (R. W.) innerhalb der Norm; als solche ist nach unseren bisherigen Erfahrungen für den Ko. P. $73-75^{\circ} \mathrm{C}$ anzusehen. Geringfügige aber deutliche Erhöhungen fanden sich bei je einem Fall von Diabetes $\left(78,5^{\circ}\right)$, multipl. Myelom $\left(76,5^{\circ}\right)$, Carcinomatose $\left(7^{\circ}\right)$, Decompens. vitium $\left(77,5^{\circ}\right)$, Sec. Anämie $\left(79,5^{\circ}\right)$, Pernic. Anämie $\left(76,4^{\circ}\right)$. Arhythmia perpetua $\left(76,5^{\circ}\right)$. Bei einem Kranken mit chronischem Ikterus fand ich (82. Refrakt. 9,26\%). Es handelt sich, wie man sieht, um Erkrankungen, bei denen Störungen des Salz- bzw. Wasserstoffwechsels oder Serumänderungen anzunehmen sind.

Sehr viel deutlichere Abweichungen des Ko. P. durfte man erwarten bei Kranken mit schweren Störungen des Wasser- und Salzstoffwechsels, wie bei hydropischen Nierenkranken. In der Tat ergaben die bisher untersuchten Fälle von Nierenkranken, soweit sie hydropisch waren, eine sehr erhebliche Erhöhung des Serumkoagulationspunktes. Werte zwischen $83-92^{\circ}$ scheinen keine Seltenheit zu sein.

Ich führe von diesen Fällen 2 charakteristische Beispiele an: I. I8 jähr. Mann. Chron. Nephritis (Nephrose?). Odeme. Eiweiß zwischen $4-5 \%$ 26. VI. $84,5^{\circ}$ Ko.P., R.W. $5,96 \%$, also starke Hydrämie. 7. VIII. bei klinisch wenig verändertem Zustand: Ko. P. $82^{\circ}$, Refr. 5,9\% Eiweiß.

2. 58 jähr. Mann. Chron. Nephritis. Herzinsuffizienz. 2. VI. $77^{\circ}$ Ko. P., Refrakt. $5,42 \%$, 4. VI. $9 \mathrm{r}^{\circ}$ Ko. P., Refrakt. $4,85 \%, 20$. VI. $98^{\circ}$ Ko. P., Refrakt. $4,81 \%$, 7. VII. $92^{\circ}$ Ko. P., Refrakt. $4,46 \%$.

Beide Fälle zeigen sehr deutlich die starke Erhöhung des Koagulationspunktes bei gleichzeitiger Hydrämie.

Bei den bisher untersuchten nicht hydropischen Nephritiden war der Ko. P. normal oder kaum erhöht, was mit den gleichfalls normalen Refraktometerwerten gut übereinstimmt.

Sehr interessant war ein Fall von Urämie (Frau T.). DaB die Refraktometrie in solchen Fällen versagt, ist bekannt; sie lieferte hier den sicher falschen Wert 10,21\%. Der Ko. $P$. war hingegen normal $\left(73,5^{\circ}\right)$. Es scheint also namentlich in derartigen Fällen, bei denen der Refraktometerwert trügerisch sein kann, die Feststellung des Ko. P. eine wertvolle Ergänzung zu sein.

Die naheliegende Untersuchung von Exsudaten und Transsudaten habe ich bisher nur bei einem Fall von Peritonitis tuberculosa durchgeführt. Der Ascites gerann bei $78,7^{\circ}$, Refrakt. $5,75 \%$.

Uber die Ergebnisse ausgedehnterer klinischer Untersuchungen werde ich später berichten. Schon jetzt aber möchte ich anregen, das Verfahren der Serumbitzekoagulation, das eine Bereicherung der klinischen Untersuchungsmethodik zu werden verspricht, bei geeigneten Fällen anzuwenden.

\section{NERVENLÄHMUNG UND NERVENREIZUNG IN DER PATHOGENESE NERVÖSER AUSFALLS- ERSCHEINUNGEN, BESONDERS BEI SPINA BIFIDA OCCULTA,}

zugleich Erwiderung an HIGIER (vgl. diese Wochenschr. Nr. 24).

$$
\text { Von }
$$

Prof. Dr. F. BRÜNING, a. o. Professor der Chirurgie an der Universität Berlin.

In einem kurzen Aufsatz, der in Nr. I5 dieser Wochenschrift erschienen ist, habe ich auf die überragende Bedeutung der Nervenreizung gegenüber der Nervenlähmung für die Entstehung trophischer Gewebsveränderungen aufmerksam gemacht. Ich konnte dies besonders deutlich beweisen für die nach Nervenverletzung auftretenden vasomotorisch-trophischen Störungen, es aber auch für mehr wie wahrscheinlich erklären bei den sog. vasomotorisch-trophischen Neurosen (Acroparaesthesie, Sclerodermie usw.).

Nun gibt es eine Art von vasomotorisch-trophischen Geschwüren, für die auf den ersten Blick die Nervenreizung gegenüber der Nervenlähmung nicht in Frage zu kommen scheint, nämlich die bei Spina bifida occulta zu beobachtenden Geschwüre an den Füßen. Denn wir waren es gewohnt, ibr Entstehen auf angeborene Nervendegeneration; also Nervenlähmung zurückzuführen.

Und doch glaube ich im folgenden den Beweis erbringen $\mathrm{zu}$ können, daß sowohl diese trophischen Gewebsveränderungen wie auch die ebenfalls bei der Spina bifida occulta zu beobachtenden Störungien der Harnentleerung Folgen eines Reizzustandes im Nervensystem sein können.

Ich kann mich hierbei zwar nicht auf persönliche Beobachtungen stützen, führe vielmehr den Beweis an der Hand von Fällen, die KATZENSTEIN ${ }^{1}$ ) und v. LICHTENBERG ${ }^{2}$ ) veröffentlicht haben.

Beide haben in Fällen von Inkontinenz bei Spina bifida occulta, von denen einzelne mit trophischen Geschwüren an den Füßen vergesellschaftet waren, operiert. Sie fanden Verwachsungen zwischen Rückenmark, Dura und äußerer Haut, als deren Folge Druck- und Zugwirkung auf das Rückenmark und die Nervenwurzeln anzunehmen sei, welche nun ihrerseits die Störungen in der Harnentleerung auslösten. Auf die dafür im einzelnen gegebene Erklärung gehe ich hier nicht näher ein.

Wichtig für unsere Betrachtungen ist es, daß durch die Operation, die in.Lösung der Verwachsungen bestand, vollständige Heilung der Störungen in der Harnentleerung und auch Heilung der trophischen Geschwüre am Fuß erzielt wurde.

Diese Fälle zeigen meines Erachtens auf das deutlichste, von welch großer Bedeutung es ist, ob wir Nervendegeneration und Nervenlähmung oder aber Nervenreizung pathogenetisch verantwortlich machen.

Betrachten wir die Störungen als Folgen einer angeborenen Nervendegeneration mit konsekutiver Nervenlähmung, wie es bisher im allgemeinen geschah, so verurteilten wir uns und die Kranken zu einer rein symptomatischen Behandlung, die gewöhnlich infolge der unvermeidbaren aufsteigenden Pyelonephritis den Eintritt des Todes nicht verhindern konnte.

Betrachten wir dagegen eine Nervenreizung als auslösendes Moment, so können wir kausale Therapie treiben, wir können durch Beseitigung des Reizzustandes im Nervensystem vollständige Heilung erzielen und so dem Tode sonst unrettbar verfallene Kranke am Leben erhalten.

Die vorstehenden kurzen Ausführungen waren im Entwurf fertig, als in Nr. 24 dieser Wochenschrift ein Artikel von HIGIER, Warschau, erschien, der sich mit meinem eingangs erwähnten Aufsatz eingehend beschäftigt und der nicht unwidersprochen bleiben darf.

1) KATZENSTEIN, Beitrag zur Pathologie und Therapie der Spina bifida occulta Arch. f. klin. Chirurg. 64, S. 607, rgor.

2) v LICHTENBERG, Die klinische Abgrenzung des Krankheitsbildes der Inksontinenz bej der Spina bifida occulta lumbodorsalis und,ihre operative Behandlung. Zeitschr. f. urol. Ch:rurg. 6, H. $5 / 6$, S. 27 , I $92 x$. 